\title{
Optimisation of stir bar sorptive extraction and liquid desorption combined with large volume injection-gas chromatography-quadrupole mass spectrometry for the determination of volatile compounds in wines
}

\author{
Elisabete Coelho ${ }^{a}$, Rosa Perestrelo ${ }^{b, d}$, Nuno R. Neng ${ }^{b}$, José S. Câmara ${ }^{d}$, \\ Manuel A. Coimbra ${ }^{a}$, J.M.F. Nogueira ${ }^{b, c}$, Sílvia M. Rocha ${ }^{a, *}$ \\ a Departamento de Química, Universidade de Aveiro, 3810-193 Aveiro, Portugal \\ ${ }^{\mathrm{b}}$ Departamento de Química e Bioquímica, Faculdade de Ciências, Universidade de Lisboa, \\ Campo Grande Ed. C8, 1749-016 Lisboa, Portugal \\ c Centro de Química e Bioquímica, Faculdade de Ciências, Universidade de Lisboa, \\ Campo Grande Ed. C8, 1749-016 Lisboa, Portugal \\ d Centro de Química da Madeira, Departamento de Química, Universidade da Madeira, \\ Campus Universitário da Penteada, 9000-390 Funchal, Portugal
}

\section{A R T I C L E I N F O}

\section{Article history:}

Received 17 March 2008

Received in revised form

13 June 2008

Accepted 19 June 2008

Published on line 27 June 2008

Keywords:

Stir bar sorptive extraction

Liquid desorption

Large volume injection

Volatile compounds

Gas chromatography-quadrupole mass spectrometry

Wine

\begin{abstract}
A B S T R A C T
Stir bar sorptive extraction and liquid desorption followed by large volume injection coupled to gas chromatography-quadrupole mass spectrometry (SBSE-LD/LVI-GC-qMS) had been applied for the determination of volatiles in wines. The methodology was optimised in terms of extraction time and influence of ethanol in the matrix; LD conditions, and instrumental settings. The optimisation was carried out by using 10 standards representative of the main chemical families of wine, i.e. guaiazulene, $E, E$-farnesol, $\beta$-ionone, geranylacetone, ethyl decanoate, $\beta$-citronellol, 2-phenylethanol, linalool, hexyl acetate and hexanol. The methodology shows good linearity over the concentration range tested, with correlation coefficients higher than 0.9821 , a good reproducibility was attained (8.9-17.8\%), and low detection limits were achieved for nine volatile compounds $\left(0.05-9.09 \mu \mathrm{gL}^{-1}\right)$, with the exception of 2-phenylethanol due to low recovery by SBSE. The analytical ability of the SBSE-LD/LVI-GC-qMS methodology was tested in real matrices, such as sparkling and table wines using analytical curves prepared by using the 10 standards where each one was applied to quantify the structurally related compounds. This methodology allowed, in a single run, the quantification of 67 wine volatiles at levels lower than their respective olfactory thresholds. The proposed methodology demonstrated to be easy to work-up, reliable, sensitive and with low sample requirement to monitor the volatile fraction of wine.
\end{abstract}

(c) 2008 Elsevier B.V. All rights reserved.

* Corresponding author at: Departamento de Química, Universidade de Aveiro, Campus de Santiago, 3810-193 Aveiro, Portugal.

Tel.: +351 234401508; fax: +351 234370084 .

E-mail address: smrocha@ua.pt (S.M. Rocha).

0003-2670/\$ - see front matter @ 2008 Elsevier B.V. All rights reserved.

doi:10.1016/j.aca.2008.06.032 


\section{Introduction}

The aroma is an important parameter of wine quality, in which the bouquet is the product of a biochemical and technological sequence, and it is influenced by the volatile varietal components (monoterpenoids, sesquiterpenoids, and $\mathrm{C}_{13}$ norisoprenoids), as well as those produced during fermentation. Alcohols, esters, acids, aldehydes, ketones, lactones, terpenoids, and phenols, representing more than 800 volatile compounds, have already been identified in grapes and wines [1]. The volatile composition of the wine is one of the most important factors to determine its aroma character and quality.

The low concentration of the majority of the volatile compounds present in a wine matrix makes enrichment as a basis for identification and quantification. For this purpose, liquid-liquid extraction (LLE) followed by gas chromatography coupled to mass spectrometry using the common quadrupole analyser (GC-MS) has been the analytical method of choice. Nevertheless, LLE is a time consuming and labour intensive technique, involving multi-step procedures and use of toxic solvents [2]. Nowadays, the solventless approaches such as solid phase microextraction (SPME) and, more recently, stir bar sorptive extraction (SBSE), showed to be environmental friendly alternatives due to its easy of use, high selectivity, high sensitivity and reproducibility, and less time consuming than the conventional techniques for which the most important theoretical considerations have been already described $[3,4]$. Similarly to SPME in SBSE, the efficiency of analyte partitioning between the polymeric phase and water, can be predicted by the octanol-water partitioning coefficients ( $\mathrm{K}_{\mathrm{PDMS} / \mathrm{w}} \approx \mathrm{K}_{\mathrm{O} / \mathrm{w}}$ ) at the equilibrium [5]. Therefore, the recovery of an analyte from the sample can theoretically be calculated through the equation $m_{\mathrm{SBSE}} / m_{0}=\left(\mathrm{K}_{\mathrm{O} / \mathrm{w}} / \beta\right) /\left(1+\left(\mathrm{K}_{\mathrm{O} / \mathrm{w}} / \beta\right)\right.$, where $m_{\mathrm{SBSE}}$ is the amount of analyte in the polydimethylsiloxane (PDMS) phase, $m_{0}$ is the total amount of analyte originally present in the sample, $\mathrm{K}_{\mathrm{O} / \mathrm{W}}$ is the octanol-water partition coefficient, $\beta\left(=V_{\mathrm{W}} / \mathrm{V}_{\mathrm{SBSE}}\right)$ is the phase ratio, $\mathrm{V}_{\mathrm{W}}$ is the volume of water and $V_{\text {SBSE }}$ is the volume of PDMS phase. Thus, the recovery of an analyte from the sample becomes only dependent of the ratio of partitioning constant $\left(\mathrm{K}_{\mathrm{O} / \mathrm{W}}\right)$ and the phase ratio $(\beta)$, between the PDMS volume of the stir bar and the water sample volume [5].

SBSE have been widely used in several type of applications, especially for the association with thermal desorption (TD) systems followed by GC-MS analysis. However, the TD units are expensive devices and, although this approach presents a remarkable sensitivity, it is not the most indicated to analyse thermolabile compounds due the very high desorption temperatures of operation. In addition, TD does not offer the opportunity of reanalysis, which is an important issue in many studies for validation purposes. Alternatively, SBSE with liquid desorption (LD) has shown very interesting features to overcome these limitations and, besides being cost-effective, it has been successfully applied to the analysis of several classes of semi-volatile compounds in many types of matrices prior to GC-MS analysis [6-9]. Meanwhile, SBSE combined with LD as far as we know was never proposed for the enrichment of volatile compounds, which can be easily per- formed by trapping the analytes followed by removal through back-extraction with a small volume (typically microliters) of a convenient organic solvent. Subsequently, a very small aliquot, i.e. $0.5-2 \mu \mathrm{L}$, of this extract is injected in the gas chromatograph for analysis. Although this approach works quite successfully, the sensitivity can be highly enhanced through the combination of LD with large volume injection (LVI) [6-9].

Although several studies have been already published using the SBSE-TD/LVI-GC-MS methodology to characterize the volatile fraction of wine $[3,4,10,11]$, the use of liquid desorption was never suggested as an alternative. The aim of the present work is the development of a novel approach for the analysis of volatile compounds using SBSE-LD followed by LVI-GC-MS and the application of the methodology to characterize the volatile components of wine. For this purpose, the most important SBSE-LD parameters were systematically optimised, namely, extraction time, influence of the ethanol matrix, back-extraction time and solvent type, and the main LVI instrumental settings. The performance of the methodology was evaluated in terms of accuracy, precision, limits of detection and linearity, and a lack-of-fit test was also performed, using for such purpose standard compounds representative of the main chemical classes usually found in the wine volatile composition, i.e. monoterpenoids, sesquiterpenoids, $\mathrm{C}_{13}$ norisoprenoids, esters, and aliphatic and aromatic alcohols. Finally, the optimised methodology was applied in real matrices, such as sparkling and table wines.

\section{Experimental}

\subsection{Samples and reagents}

White sparkling wine (WSW), and white table wine (WTW) and red table wine (RTW) were used. Their ethanol content varied between 10 and $14 \%$.

Analytical grade ethanol (99.8\%, Riedel-de Haën), methanol (MeOH; 99.9\%, Fluka), acetonitrile (ACN; 99.9\%, Fluka), diethyl ether (99.5\%, Riedel-de Haën), acetone (99.9\%, Fluka), 2propanol (99.5\%, Aldrich), n-pentane (99\%, Riedel-de Haën), tartaric acid (foodstuff grade, José M. Vaz Pereira), and $\mathrm{NaOH}$ (98\%, AnalaR) were used. Ultra-pure water was obtained from a Milli Q system (Millipore, Bedfords, MA, USA). Hexanol (98\%), hexyl acetate (>99\%), linalool (98.5\%), 2-phenylethanol (99\%), $\beta$-citronellol (95\%), ethyl decanoate (>99\%), geranylacetone (98\%), $\beta$-ionone (97\%), and $E, E$-farnesol (96\%) standards were supplied from Sigma-Aldrich Química S.A. (Madrid, Spain) and guaiazulene (>98\%) standard was supplied from TCI Europe N.V. (Zwijndrecht, Belgium). The stock solutions of individual standards were prepared in analytical grade ethanol.

\subsection{Optimisation of SBSE conditions}

This step was carried out by using wine model solutions fortified with standards, which were prepared from $27 \mathrm{~mL}$ of an aqueous solution of $0.5 \%$ tartaric acid adjusted with $\mathrm{NaOH}$ at $\mathrm{pH} 3.5$, then was added to $2.8 \mathrm{~mL}$ of absolute ethanol spiked with $200 \mu \mathrm{L}$ of a mixture of the 10 standards, in a total of $30 \mathrm{~mL}$. Each wine model solution was introduced into a glass vial (30 mL; Macherey-Nagel, Düren, Germany), a stir bar (Twister; 
Gerstel, Müllheim a/d Ruhr; Germany) containing a PDMS coating film ( $0.5 \mathrm{~mm}$ thick; $10 \mathrm{~mm}$ long, $24 \mu \mathrm{L})$ was immersed, and the vial was closed with a seal (aluminium seals with PTFE septa) using a manual crimper (Agilent Technologies, Little Falls, DE, USA). Assays were performed in a fifteenth agitation point plate (Variomag Multipoint komet, Thermo Fisher Scientific Inc., Waltham, MA, USA) at room temperature $\left(20^{\circ} \mathrm{C}\right)$, with extraction times of 15,30 and $60 \mathrm{~min}$ and a rotation speed of $800 \mathrm{rpm}$. The influence of ethanol matrix was tested for three contents, e.g. 10,12 , and $14 \%(\mathrm{v} / \mathrm{v})$.

To evaluate the best LD conditions, several assays using back-extraction solvents (pentane, diethyl ether, $\mathrm{MeOH}$, and azeotropic mixtures constituted by $\mathrm{MeOH}$ :acetone, $\mathrm{MeOH}$ : ACN, MeOH:pentane, MeOH:diethyl ether, ACN:pentane, acetone:pentane and 2-propanol:pentane) were also performed. For back-extraction purposes, the stir bars were placed into 250- $\mu \mathrm{L}$ glass flat-bottom inserts filled with $200 \mu \mathrm{L}$ of solvent inside a glass vial, or into $2 \mathrm{~mL}$ glass vials filled with $1 \mathrm{~mL}$ of solvent for ensuring the total immersion. The back-extraction was performed by using ultrasonic treatment (Branson 3510, Branson Ultrasonic Corporation, Danbury, USA) and desorption time was tested for 15 and $30 \mathrm{~min}$ at constant temperature $\left(25^{\circ} \mathrm{C}\right)$. After back-extraction, the stir bars were removed by means of a magnetic rod and the vials were closed with seals, using a hand crimper, and placed in the automatic liquid sampler tray for LVI-GC-qMS analysis. After each extraction, the stir bars were cleaned to dryness under a stream of purified nitrogen followed by a cleaning with ACN. All the experiments were performed at least in triplicate.

\subsection{Instrumental settings}

LVI-GC-qMS analysis were performed on an Agilent 6890 Series gas chromatograph equipped with an Agilent 7683 automatic liquid sampler tray (Agilent 7683, Agilent Technologies, Little Falls, DE, USA) coupled to an Agilent $5973 \mathrm{~N}$ mass selective detector (Agilent Technologies, Little Falls, DE, USA). A programmed temperature vaporization injector (PTV) with a septumless sampling head having a baffled liner (SLH; Gerstel, Mülheim a/d Ruhr, Germany) was used, operating in the solvent vent mode with liquid nitrogen as inlet cooling. For LVI, the solvent vent injection mode was performed (vent time: $0.30 \mathrm{~min}$; flow rate: $5,10,20$, and $50 \mathrm{~mL} \mathrm{~min}^{-1}$; pressure: 0 psi; purge: $60 \mathrm{~mL} \mathrm{~min}^{-1}$ at $2 \mathrm{~min}$ ), for which the inlet temperature was programmed from 0,10 , and $20(0.35 \mathrm{~min})$ to $300^{\circ} \mathrm{C}$ at a rate of $600^{\circ} \mathrm{C} \mathrm{min}{ }^{-1}$ and, subsequently, decreased to $200^{\circ} \mathrm{C}$ (held until end) at a rate of $50^{\circ} \mathrm{C} \mathrm{min}^{-1}$. The injection volume and speed were $20 \mu \mathrm{L}$ and $100 \mu \mathrm{L} \mathrm{min}^{-1}$, respectively. GC analysis was performed on a TRB-5MS $(30 \mathrm{~m} \times 0.25 \mathrm{~mm}$ i.d., $0.25 \mathrm{~mm}$ film thickness) capillary column (5\% diphenyl, 95\% dimethylpolysiloxane; Teknokroma, Spain). Helium as carrier gas was maintained in the constant pressure mode and the inlet pressure was $21.36 \mathrm{psi}$ with a flow rate of $2.8 \mathrm{~mL} \mathrm{~min}^{-1}$. The oven temperature was programmed from $40^{\circ} \mathrm{C}$ at $2{ }^{\circ} \mathrm{C} \mathrm{min}^{-1}$ to $175^{\circ} \mathrm{C}$, then at $10^{\circ} \mathrm{C} \mathrm{min}^{-1}$ to $220^{\circ} \mathrm{C}$ ( $5 \mathrm{~min}$ ) in a $77.00 \mathrm{~min}$ running time. The transfer line, ion source, and quadrupole (q) analyser temperatures were maintained at 280,230 , and $150^{\circ} \mathrm{C}$, respectively. A solvent delay of $4 \mathrm{~min}$ was selected. In the full-scan mode, electron ionization mass spectra in the range $35-550 \mathrm{~m} / \mathrm{z}$ were recorded at
$70 \mathrm{eV}$ electron energy with an ionization current of $34.6 \mu \mathrm{A}$. The mass spectra were obtained in full-scan mode and compared with the Wiley's library reference spectral bank (G1035B; Rev D.02.00; Agilent Technologies, Santa Clara, CA, USA). Data recording and instrument control were performed by the MSD ChemStation software (G1701CA; version C.00.00; Agilent Technologies, Santa Clara, CA, USA). For the determination of the retention indices (RI) a $C_{10}-C_{24} n$-alkanes series was used.

\subsection{Analytical curves and wine analysis}

Wine samples $(30 \mathrm{~mL})$ were analysed under the previously optimised experimental conditions: $60 \mathrm{~min}$ of extraction time, $10 \%$ ethanol content, pentane as the desorption solvent, $15 \mathrm{~min}$ of back-extraction time, $10 \mathrm{~mL} \mathrm{~min}^{-1}$ for the solvent vent flow rate, and $10^{\circ} \mathrm{C}$ for the inlet temperature.

For quantification purposes, analytical curves were performed for guaiazulene, E,E-farnesol, $\beta$-ionone, geranylacetone, ethyl decanoate, $\beta$-citronellol, 2-phenylethanol, linalool, hexyl acetate and hexanol, under the concentration range shown in Table 1 . The analytical plots were made in a wine model solution ( $30 \mathrm{~mL}$ ) with $10 \%$ ethanol, $0.5 \%$ tartaric acid adjusted to $\mathrm{pH} 3.5$ with $\mathrm{NaOH}$ fortified with $200 \mu \mathrm{L}$ of a mixture of all standards. Beyond these 10 standards representing the main chemical families in wine, other volatiles from these chemical families were also detected in wine. For the quantification of these, the structure related standard (functional group and chemical structure) were used: the monoterpenoids were quantified with linalool analytical plot, cyclic sesquiterpenes were quantified with guaiazulene, linear sesquiterpenoids were quantified with $E, E$-farnesol, $C_{13}$ norisoprenoids were quantified with $\beta$-ionone, esters until eight carbon skeleton were quantified with hexyl acetate, esters with more than nine carbons skeleton were quantified with ethyl decanoate, and aliphatic and aromatic alcohols were quantified with hexanol and 2-phenylethanol, respectively.

Recovery tests comprising the 10 standards were done in sparkling and table wines. The wines were fortified with a mixture of the 10 compounds: guaiazulene $\left(3.5 \mu \mathrm{gL}^{-1}\right), \quad E, E$-farnesol $\left(93 \mu \mathrm{gL}^{-1}\right), \quad \beta$-ionone $\left(23 \mu \mathrm{gL}^{-1}\right)$, geranylacetone $\left(27 \mu \mathrm{gL}^{-1}\right)$, ethyl decanoate $\left(91 \mu \mathrm{gL}^{-1}\right)$, $\beta$-citronellol $\left(320 \mu \mathrm{gL}^{-1}\right), \quad$ 2-phenylethanol $\left(31.8 \mathrm{mgL}^{-1}\right)$, linalool $\left(282 \mu \mathrm{gL}^{-1}\right)$, hexyl acetate $\left(435 \mu \mathrm{gL}^{-1}\right)$ and hexanol $\left(378 \mu \mathrm{gL}^{-1}\right)$. Although the concentration range reported in Table 1 for citronellol and linalool, linearity was observed until concentrations of $512 \mu \mathrm{gL}^{-1}$ for both compounds (data not shown). These values were plotted against $K_{\mathrm{O} / \mathrm{w}}$ values for each standard, which were calculated with the SRC-KOWWIN v1.67 software package, according to a fragment constant estimation method [12].

\section{Results and discussion}

\subsection{Optimisation of the parameters affecting the SBSE-LD/LVI-GC-qMS}

\subsubsection{Effect of the SBSE conditions}

Several SBSE parameters were performed using standard conditions, according to previous work [3]. During our preliminary 


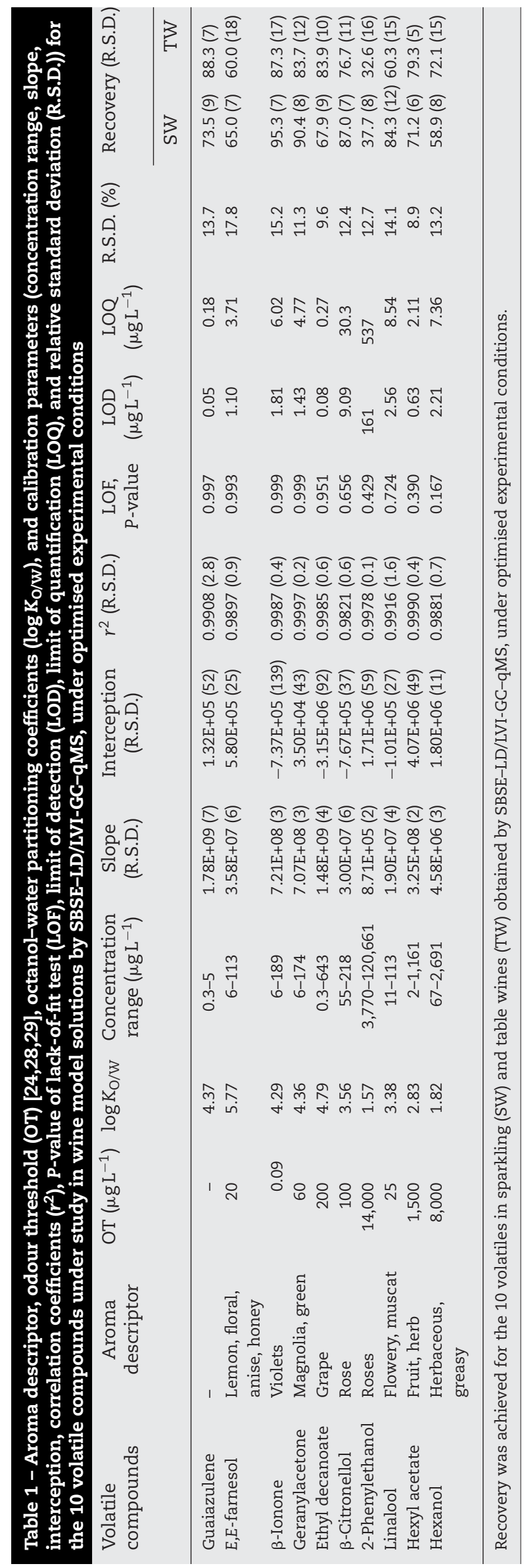

studies, the same sample matrix, vial volume, and PDMS coating $(24 \mu \mathrm{L})$ were used in a two-phase system, i.e. a liquid sample-stir bar. A PDMS volume of $24 \mu \mathrm{L}$ was chosen since this polymer is very effective for non-polar volatiles and its low amount used minimizes the size of the stir bar which is a key parameter in the back-extraction assays. Thus, the use of a minimum amount of solvent for LD is very convenient since avoiding the undesirable solvent evaporation step usually performed for sensitivity enhancement; it minimizes the possible volatile losses.

Based on the theory reported by Baltussen et al. [5], the extraction time was evaluated by stirring the sample during three different periods, i.e. 15, 30, and $60 \mathrm{~min}$. Fig. $1 \mathrm{a}$ shows that for the compounds with higher volatility and functional alcohol groups (e.g. hexanol, linalool, 2-phenylethanol, and $\beta$-citronellol) no advantages were observed for extraction times higher than $15 \mathrm{~min}$. Nevertheless, for the remaining compounds that present low volatility (e.g. ethyl decanoate, geranylacetone, $\beta$-ionone, E,E-farnesol, guaiazulene, and hexyl acetate) slight signal increments from 15 to $30 \mathrm{~min}$ and larger signal increments from 30 to $60 \mathrm{~min}$ were noticed. For the case of ethyl decanoate, geranylacetone, $\beta$-ionone, E,Efarnesol, and guaiazulene, the GC peak area almost double (Fig. 1a). No longer times were evaluated, since several authors had point out that for periods higher than $60 \mathrm{~min}$, no advantages were observed for volatile enrichment purposes [8,9]. Therefore, the extraction time of $60 \mathrm{~min}$ was set for further experiments.

The influence of the ethanol matrix was evaluated by using matrices with 10,12 , and $14 \%$ ethanol. The data obtained is depicted in Fig. 1b, in which it is shown that, for these three ethanol contents, in general, the GC peak area of the volatile compounds did not differ significantly, with the exception of $\beta$-ionone for $14 \%$ in ethanol. The non-polar compounds, with low water solubility, are better dissolved in the ethanolic medium. Then, it was expected that for larger amounts of ethanol in the matrix these compounds could be lower recovered. This behaviour will be more effective with higher amounts of ethanol, like in sweet wines and distillate drinks, although for table wines the ethanol content seems to be a negligible parameter, this methodology could be also be applied to spirits if they was diluted to the rage under study. Consequently, the further studies using wine model solutions were performed with $10 \%$ ethanol.

\subsubsection{Effect of the $L D$ conditions}

In a preliminary study, different desorption solvents were tested for the back-extraction process, including $\mathrm{MeOH}$ and ACN, since they are the most used for LD of the semi-volatile compounds analysed by SBSE [6-9]. Nevertheless, this analytical approach needs a solvent switch step, i.e. evaporation to dryness of the polar solvent used for desorption followed by addition of an organic solvent more suitable for LVI in solvent vent mode during GC-qMS analysis. In our particular case, the solvent switch step should be avoided to prevent possible losses of some volatile compounds during evaporation. Once the volatile fraction of the wine samples present high volatility, it is necessary to ensure that the extraction of these compounds is representative of the real composition. Thereby, by using this approach, it is also important to avoid 

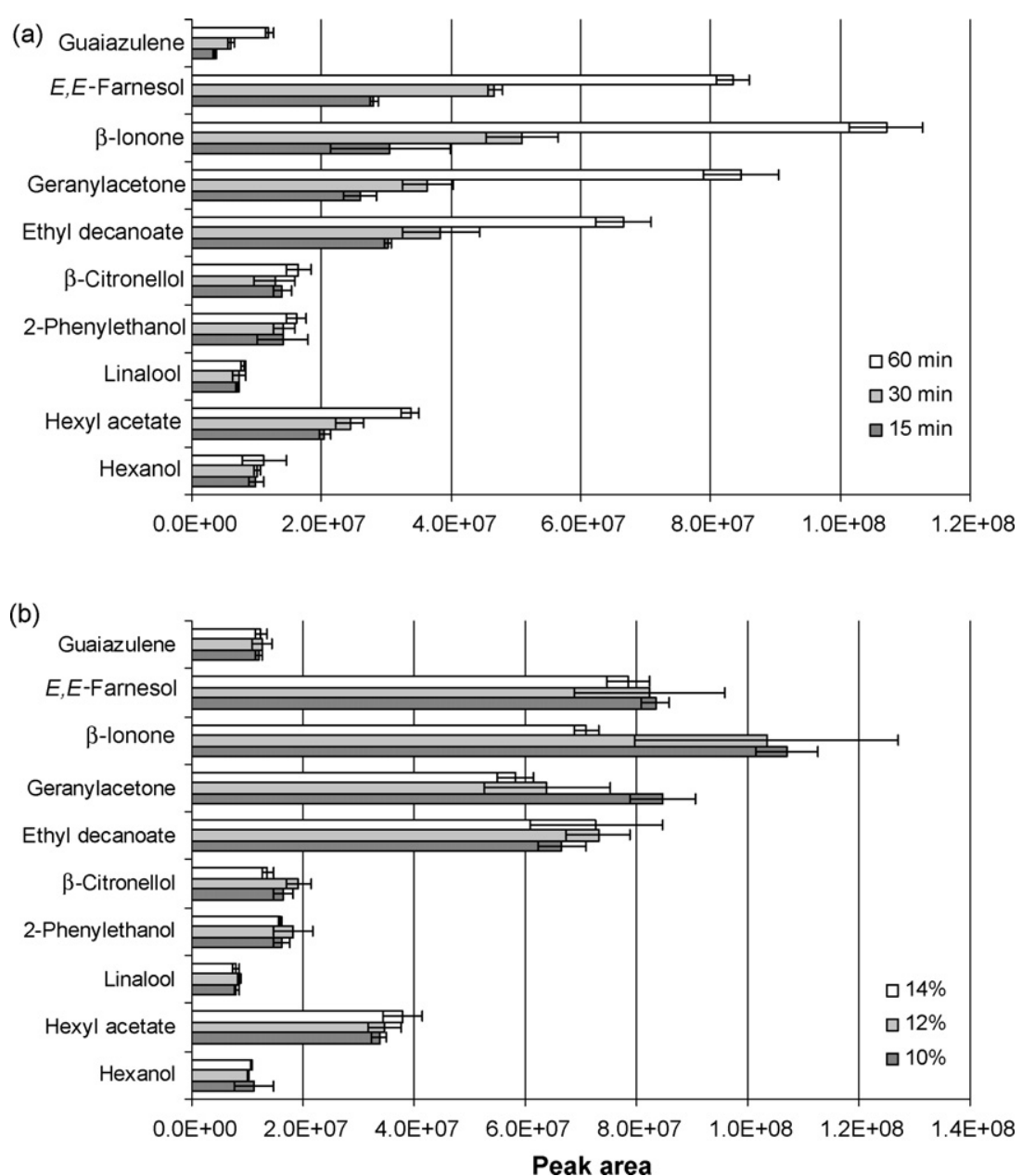

Fig. 1 - Effect of the extraction time (a) and matrix ethanol influence (b), on the peak area of the 10 volatile compounds under study by SBSE-LD/LVI-GC-qMS.

fronting peaks and guarantee precision, excluding ACN as a suitable solvent for LVI in solvent-vent mode. In the first step, He flow rate at $150 \mathrm{~mL} \mathrm{~min}^{-1}$ was used, based on the experimental conditions reported for the analysis of semi-volatile compounds [6-9]. However, this condition was not considered acceptable since from the 10 compounds under study, only five, i.e. ethyl decanoate, geranylacetone, $\beta$-ionone, $E, E$-farnesol, and guaiazulene were detected. These were the compounds with the higher molecular mass, whereas the most volatile ones were not detected at all. Therefore, instead of $150 \mathrm{~mL} \mathrm{~min}^{-1}$, it was used $50 \mathrm{~mL} \mathrm{~min}^{-1}$. However, the chromatographic performance of $\mathrm{MeOH}$ to this flow rate was unacceptable, presenting peaks with fronting. The chromatographic performance is very dependent from the He flow rate against solvent used; although it were detected more three volatile compounds (i.e. hexyl acetate, linalool and $\beta$-citronellol), and the peak areas were, in general, 1000 times lower. As a result, it was decided to test other solvents individually with lower boiling points (bp), such as pentane $\left(\mathrm{bp}=35^{\circ} \mathrm{C}\right)$ and diethyl ether $\left(\mathrm{bp}=35^{\circ} \mathrm{C}\right)$, as well as azeotropic mixtures such as $\mathrm{MeOH}$ :acetone $\left(\chi_{\mathrm{MeOH}}=0.24\right.$; $\left.\mathrm{bp}=54^{\circ} \mathrm{C}\right), \mathrm{MeOH}$ :diethyl ether $\left(\chi_{\mathrm{MeOH}}=0.05 ; \quad b p=32^{\circ} \mathrm{C}\right)$, MeOH:pentane $\quad\left(\chi_{\mathrm{MeOH}}=0.19 ; \quad b p=30^{\circ} \mathrm{C}\right), \quad$ ACN:pentane $\left(\chi_{\mathrm{ACN}}=0.10 ; \quad \mathrm{bp}=25^{\circ} \mathrm{C}\right), \quad$ acetone:pentane $\quad\left(\chi_{\text {acetone }}=0.17\right.$; $\left.\mathrm{bp}=26^{\circ} \mathrm{C}\right) \quad$ and $\quad$ 2-propanol:pentane $\quad\left(\chi_{2}\right.$-propanol $=0.14$; $\mathrm{bp}=26^{\circ} \mathrm{C}$ ) [13]. From all azeotropic mixtures tested, $\mathrm{MeOH}$ :acetone showed the best chromatographic signal. Additionally, with this particular mixture it was also evaluated the LD performance by desorption the stir bars with $\mathrm{MeOH}$ prior the addition of acetone reaching a equimolar proportion, using LVI with a solvent flow vent rate of $\mathrm{He}$ of $50 \mathrm{~mL} \mathrm{~min}^{-1}$ (Fig. 2a). In both cases, the reproducibility, expressed as error bars in Fig. 2a, was low, especially in the case of the $\mathrm{MeOH}$ :acetone azeotropic mixture. The results obtained with diethyl ether were unacceptable, as they presented peaks with fronting and do not allowing the detection of all standards. All the experiments carried out for selection of the back-extraction solvent indicated that pentane showed higher affinity for the back-extraction of the volatiles under study, showing standard deviation (error bars in Fig. 2a) lower than those obtained with other solvents and presenting superior recovery for the compounds with higher volatility, such as, hexanol, hexyl acetate, linalool, and 2-phenylethanol. Furthermore, no fronting peaks were achieved with pentane. Therefore, pentane was selected as the best back-extraction solvent for the LD process.

The time for the back-extraction process was tested for 15 and $30 \mathrm{~min}$ by using $250 \mu \mathrm{L}$ glass flat-bottom inserts with 

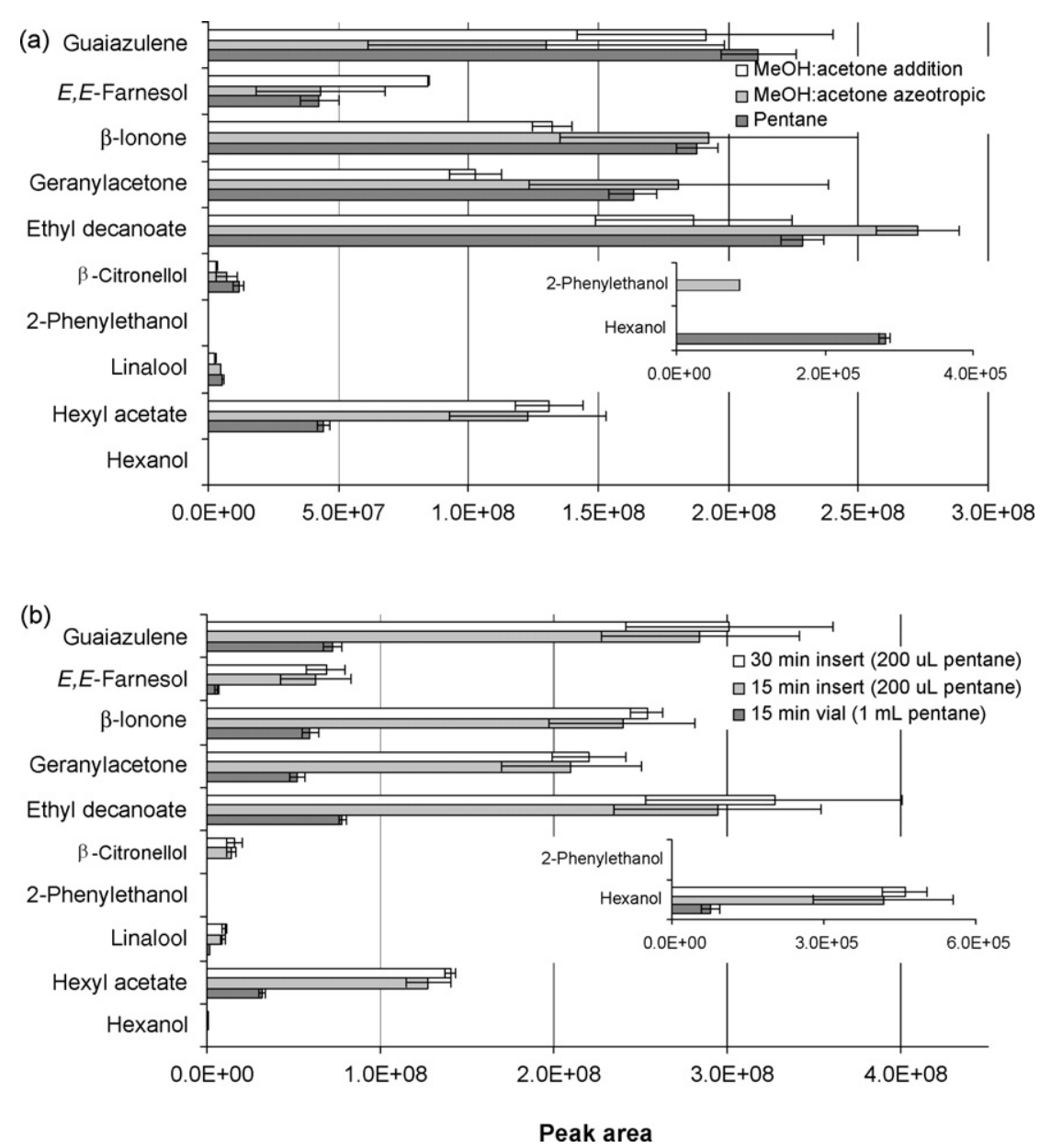

Fig. 2 - Effect of the back-extraction solvent type (a) and desorption time (b), on the peak area of the 10 volatile compounds under study by SBSE-LD/LVI-GC-qMS.

$200 \mu \mathrm{L}$ of pentane, and for $15 \mathrm{~min}$ by using $2.0 \mathrm{~mL}$ vials having $1 \mathrm{~mL}$ of pentane, ensuring the total stir bar immersion in both cases. These assays were performed under ultrasonic treatment at constant temperature $\left(25^{\circ} \mathrm{C}\right)$ and the results obtained are shown in Fig. $2 b$. The desorption experiments inside the vials were performed during $15 \mathrm{~min}$ and the peak areas were 73 (ethyl decanoate) to $92 \%$ (E,E-farnesol) lower than with the glass flat-bottom insert alone, which reflects the diluting effect when a larger solvent volume was used. Negligible differences were observed for 15 and $30 \mathrm{~min}$ by using the $250 \mu \mathrm{L}$ glass flat-bottom insert with $200 \mu \mathrm{L}$ of pentane and, according to previous works $[8,9]$, no advantages were obtained for longer periods than $15 \mathrm{~min}$. The following studies were performed for $15 \mathrm{~min}$ by using the $250 \mu \mathrm{L}$ glass flat-bottom insert with $200 \mu \mathrm{L}$ of pentane.

\subsubsection{Effect of the LVI conditions}

Due to the dependence of the inlet purge flow rate and temperature during LVI in the solvent vent mode, pentane was tested under four flow rates, i.e. 5, 10, 20, and $50 \mathrm{~mL} \mathrm{~min}^{-1}$. Fig. 3a shows that the He flow which allows better recovery for all standards was $5 \mathrm{~mL} \mathrm{~min}^{-1}$, however unacceptable chromatographic shape resulting in undesirable fronting was observed. The lower recoveries were attainted with $50 \mathrm{~mL} \mathrm{~min}^{-1}$. He flow rates of 10 and $20 \mathrm{~mL} \mathrm{~min}^{-1}$ showed similar recoveries, with the exception of hexyl acetate, where $10 \mathrm{~mL} \mathrm{~min}^{-1}$ promoted the higher recovery. Thus, $10 \mathrm{~mL} \mathrm{~min}^{-1}$ was chosen as the purge vent for the following experiments.

The initial inlet purge temperature during solvent vent mode is also a critical parameter that should be optimised since lower temperatures allow a better trapping of the volatiles. This has the drawback of decreasing, however, the chromatographic signal of the low molecular weight compounds. For the three temperatures tested, the recovery of the volatile compounds increase from the experiment with inlet temperature of 20 to $10^{\circ} \mathrm{C}$, with the exception of ethyl decanoate, but decrease when the inlet temperature was $0^{\circ} \mathrm{C}$ (Fig. 3b). Furthermore, the higher reproducibility was observed for $10^{\circ} \mathrm{C}$. Therefore, no advantages were obtained by using temperatures below $10^{\circ} \mathrm{C}$, as shown in Fig. 3b. For the 10 volatile compounds under study, the inlet temperature at $0{ }^{\circ} \mathrm{C}$ gave, in general, unexpectedly smaller peak areas compared with those obtained at 10 or $20^{\circ} \mathrm{C}$. The mass transfer of the trapped analytes from the PTV inlet to the column is less effective at $0^{\circ} \mathrm{C}$ due probably to water condensation and frosting of the injection port, a phenomenon that was also reported by León et al. [14]. Therefore, as the higher reproducibility and recovery were observed for $10^{\circ} \mathrm{C}$ this was the cryofocusing inlet temperature selected for the further experiments. 

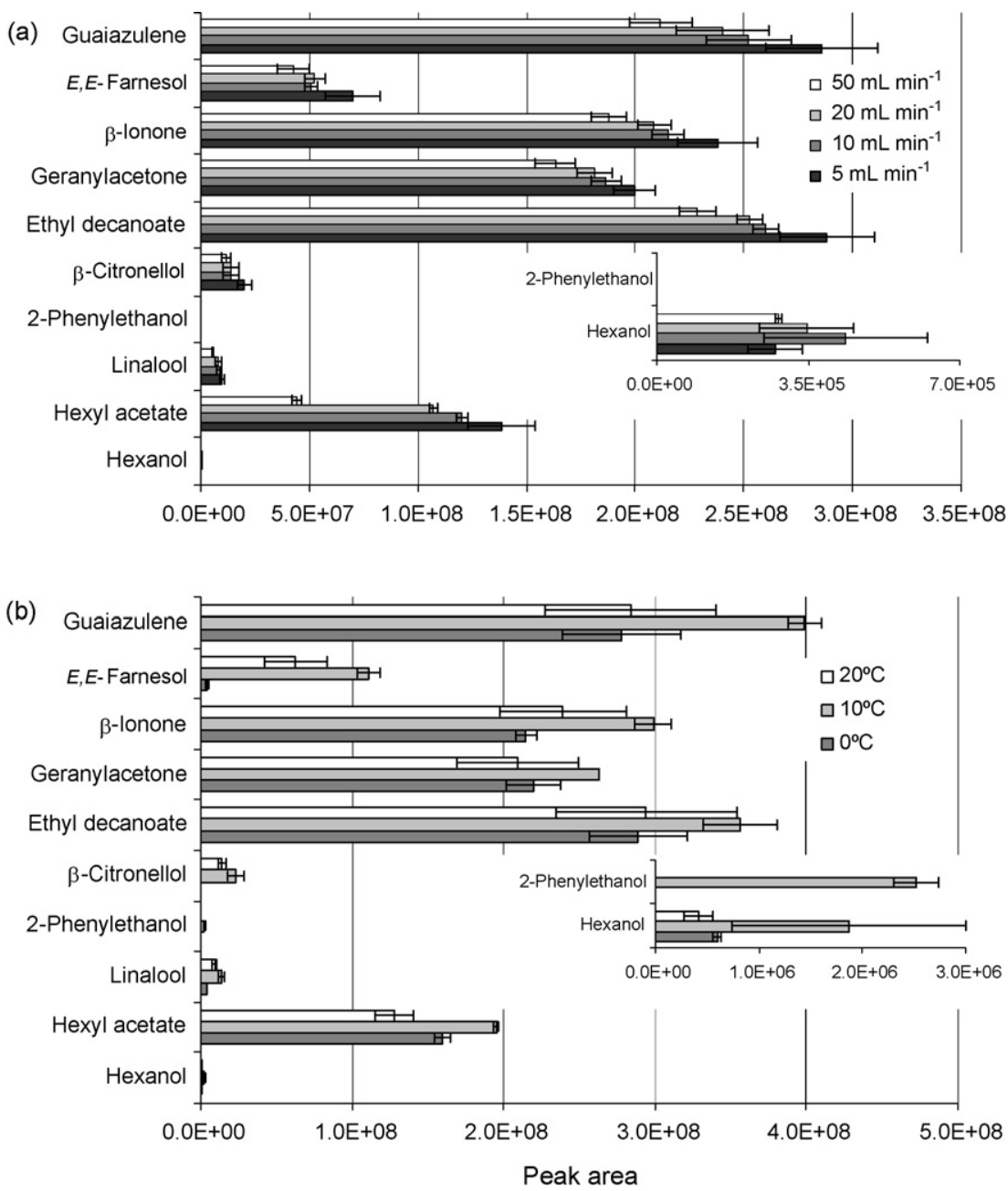

Fig. 3 - Effect of the inlet purge vent flow rate (a) and temperature (b) on the peak area of the 10 volatile compounds under study by SBSE-LD/LVI-GC-qMS.

\subsection{Validation of the SBSE-LD/LVI-GC-qMS methodology}

The aroma descriptor, odour threshold, octanol-water partitioning coefficients $\left(\log \mathrm{K}_{\mathrm{O} / \mathrm{W}}\right),(\mathrm{OT})$, limits of detection (LOD) and quantification (LOQ), and the calibration parameters of 10 standards under the optimised experimental conditions are shown in Table 1 . The analytical plots were constructed with a minimum of five concentration levels and in triplicate. The LODs (i.e. the minimum amount of each compound that can be reliably distinguished) of the methodology were achieved as the amount of each compound to provide a signal-to-noise ratio of 3 above the variability; the LOQs were achieved as the amount of each compound to provide a signal-to-noise ratio of 10 above the variability. The lack-of-fit test performed for the analytical plots, showed for all curves no lack of linear fit for a $\alpha=0.05$, as all $P$-values were higher than 0.05 . Each standard under study may contribute individually to the solution aroma, with several fruity and floral notes, according to its aroma descriptor, if present in concentration equal or higher than its respective OT (Table 1). The exception was the guaiazulene, which aroma descriptor was not found in the lit- erature. The LODs and LOQs obtained by SBSE-LD/LVI-GC-qMS were much lower than their respective OT, which indicates that this methodology, if used for wines, allows inferring the wine aroma properties based on its volatile composition.

Correlation coefficients, higher than 0.9821 , were obtained for the 10 standards. The relative standard deviation (R.S.D.) was calculated by performing six consecutive extractions to the lower concentration of each volatile compound, which ranged from 8.9 to $17.8 \%$ for hexyl acetate and E,E-farnesol, respectively. The recovery ranged from 37.7 to $95.3 \%$ in sparkling wine, and from 32.6 to $87.3 \%$ in table wine, being 2-phenylethanol the compound that exhibited the lower recovery and $\beta$-ionone the higher recovery, in both wines.

Fig. 4 depicts the average recovery for the 10 standards in sparkling and table wines, under the conditions, plotted against their corresponding $\log \mathrm{K}_{\mathrm{O} / \mathrm{W}}$ (Table 1). The equilibrium theoretical line was calculated assuming a $30 \mathrm{~mL}$ of ultra-pure water $\left(V_{W}\right)$ and a stir bar coated with $24 \mu \mathrm{L}\left(\mathrm{V}_{\mathrm{SBSE}}\right)$ of PDMS, for which a phase ratio $\left(\beta=V_{\mathrm{W}} / \mathrm{V}_{\mathrm{SBSE}}\right)$ of 1153.85 was established. The $\log K_{\mathrm{O} / \mathrm{w}}$ values ranged between 1.57 (2-phenylethanol) and 5.77 (E,E-farnesol) (Table 1). The recovery values obtained 

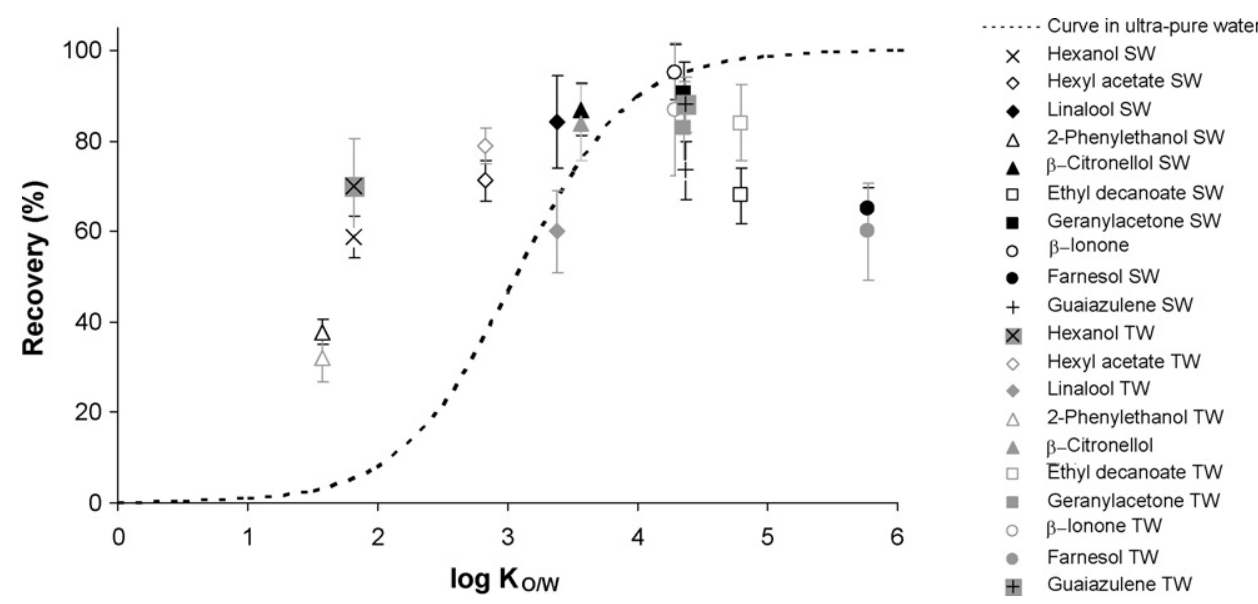

Fig. 4 - Theoretical (ultra-pure water) and experimental (SW-sparkling wine and TW-table wine) recovery plotted against $\log K_{O / w}$ for the 10 volatile compounds by SBSE-LD/LVI-GC-qMS, under optimised experimental conditions.

in sparkling and table wines were similar, with the exception of the values obtained for linalool.

According to the SBSE theory, the distribution coefficients of the analytes between the PDMS and the water matrix $\left(K_{\mathrm{PDMS} / \mathrm{w}}\right)$ are strongly correlated with the corresponding $\mathrm{K}_{\mathrm{O} / \mathrm{w}}$. It is therefore expected that the non-polar compounds have a $\log K_{\mathrm{O} / \mathrm{W}}>4.5$. From the 10 volatiles under study, only $E, E-$ farnesol $\left(\log \mathrm{K}_{\mathrm{O} / \mathrm{W}}=5.77\right)$ and ethyl decanoate $\left(\log \mathrm{K}_{\mathrm{O} / \mathrm{W}}=4.79\right)$ exhibit $\log K_{\mathrm{O} / \mathrm{W}}>4.5$; other three compounds, guaiazulene, geranylacetone, and $\beta$-ionone presented $\mathrm{K}_{\mathrm{O} / \mathrm{w}}$ close to 4.5 . It is therefore expected that the non-polar compounds should have larger affinity for the PDMS polymeric coating of the stir bars, which in the theoretical SBSE curve recovery will be greater than $96 \%$. For instance, for $\beta$-ionone, having a $\log \mathrm{K}_{\mathrm{O} / \mathrm{W}}$ of 4.29 , a theoretical recovery of $94.4 \%$ should be expected. Indeed, the experimental average recovery in ultra-pure water obtained for $\beta$-ionone was 95.3 and $87.3 \%$, in sparkling and table wines, respectively, and therefore, the agreement among the expected and the experimental data was good. In general, this example with a volatile compound ( $\beta$-ionone) clearly illustrates the behaviour for the non-polar end of the $\mathrm{K}_{\mathrm{O} / \mathrm{W}}$ scale, where experimental data fit the theoretical line very well. The exception was observed for ethyl decanoate and E,E-farnesol, which the hypotheses of ethanol matrix influence, could explain this behaviour. These compounds have low polarity but they are ethanol soluble, and ethanol could act as a co-solvent. Contrarily, 2-phenyletanol and hexanol should present theoretical low recoveries, i.e. ca. 3 and 5\%. However, the experimental data was 37.7 and 58.9\%, respectively, in sparkling wine, and 32.6 and $87.3 \%$ in table wine. In this case, the ethanol seems to play a support role acting as an interface to make the sorption process of these compounds more extensive by the PDMS polymer. Therefore, the wine matrix, in a global way, could play particular synergisms, performing an important role on the efficient recovery of the volatile compounds.

\subsection{Application to wines}

To demonstrate the analytical ability of the SBSE-LD/LVIGC-qMS to characterise the volatile components of wine, assays were performed in real matrices: a sparkling wine, and a white and a red table wines. Thus, beyond several volatile compounds detected by this methodology, this manuscript was focused only on the analysis of the five most important chemical classes. Table 2 shows the concentration of 67 volatile compounds detected in sparking and/or table wines, distributed as following: monoterpenoids (14), sesquiterpenoids (11), $C_{13}$ norisoprenoids (4), esters (29) and alcohols (9).

The applicability of the SBSE-LD/LVI-GC-qMS methodology for the study of the wine volatile composition may be used for different purposes, such as definition of the varietal volatile profile closely related with grape origin traceability, verification if the volatile compounds are present in concentrations that might contribute to the wine aroma, and/or detection of compounds that may promote off-flavours, such as $\mathrm{C}_{6}$ alcohols. Examples comprise these applications will be described.

Sparkling wine was produced according to the Champagnois methodology that is obtained from a base wine submitted to a second fermentation inside the bottle. During the second fermentation, more esters are produced by the yeast metabolism, and also by the bulk reactions that could take place between alcohols and acids. Consequently, it is expected a large number of fermentative volatile compounds (esters and alcohols) in this wine. The fermentative compounds represent in terms of concentration $99 \%$ of volatile compounds under study, where 2-phenylethanol, ethyl octanoate, ethyl hexanoate, diethyl succinate and ethyl decanoate were the major ones, with respectively 41686, 706, 702, 180 and $136 \mu \mathrm{gL}^{-1}$. For all types of wines, esters represented the chemical family that included the higher number of compounds; however the WSW presented higher number of esters (25) than the WTW (20) and RTW (20), although not exhibiting the highest ester concentration. These differences are expected as the three types of wines under study were provided from different winemaking processes, as well as from different varieties, geographical origins and harvests.

Beyond the fermentative compounds, the varietal ones are important volatile components of wines due mainly to their 
Table 2 - Concentration of volatile compounds of the main chemical classes detected in white sparkling wine (WSW), white table wine (WTW) and red table wine (RTW) obtained by SBSE-LD/LVI-GC-qMS

\begin{tabular}{|c|c|c|c|c|c|c|c|c|}
\hline \multirow[t]{2}{*}{$\mathrm{RI}_{\text {calc }}{ }^{\mathrm{a}}$} & \multirow[t]{2}{*}{$\mathrm{RI}_{\text {lit }} \mathrm{b}$} & \multirow[t]{2}{*}{ Volatile compounds } & \multicolumn{6}{|c|}{ Concentration $\left(\mu g \mathrm{~L}^{-1}\right)$} \\
\hline & & & \multicolumn{2}{|c|}{ WSW } & \multicolumn{2}{|c|}{ WTW } & \multicolumn{2}{|c|}{ RTW } \\
\hline \multicolumn{9}{|c|}{ Monoterpenoids } \\
\hline 985 & - & Geranic oxide (linaloyl oxide) & 23.5 & $(8)^{c}$ & 170.0 & $(10)$ & 37.1 & $(10)$ \\
\hline 1002 & 973 & Z-Herboxide & 16.6 & $(12)$ & - & - & - & - \\
\hline 1008 & 988 & E-Herboxide & 27.6 & $(6)$ & $<\mathrm{LOD}$ & - & - & - \\
\hline 1012 & 1033 & Limonene & - & - & 88.6 & (7) & - & - \\
\hline 1021 & - & n.i. monoterpene $(\mathrm{m} / \mathrm{z} 93,105,121)$ & - & - & 76.2 & (17) & - & - \\
\hline 1024 & - & n.i. monoterpene $(\mathrm{m} / \mathrm{z} 93,121,136)$ & - & - & 40.4 & (7) & 34.8 & $(9)$ \\
\hline 1044 & 1087 & $\alpha$-Terpinolene & 10.9 & $(10)$ & 98.5 & $(18)$ & - & - \\
\hline 1053 & 1098 & Linalool & 17.6 & $(14)$ & - & - & - & - \\
\hline 1081 & 1131 & Nerol oxide & 55.2 & (7) & 144.9 & $(10)$ & - & - \\
\hline 1085 & - & n.i. monoterpene $(\mathrm{m} / \mathrm{z} 71,93,121)$ & - & - & 49.5 & $(12)$ & - & - \\
\hline 1210 & - & n.i. monoterpene $(\mathrm{m} / \mathrm{z} 93,121,136)$ & - & - & 63.3 & $(22)$ & 96.2 & (29) \\
\hline 1216 & - & n.i. monoterpene $(\mathrm{m} / \mathrm{z} 93,69,136)$ & - & - & 44.2 & (23) & 66.1 & (19) \\
\hline 1233 & 1189 & $\alpha$-Terpineol & 75.6 & $(11)$ & $<\mathrm{LOD}$ & - & - & - \\
\hline 1252 & 1260 & Geraniol & 29.4 & $(12)$ & 271.8 & $(12)$ & - & - \\
\hline Subto & $\left.\mathrm{L}^{-1}\right)$ & & 256.3 & & 1047.6 & & 234.3 & \\
\hline \multicolumn{9}{|c|}{ Sesquiterpenoids } \\
\hline 1462 & - & n.i. sesquiterpene $(\mathrm{m} / \mathrm{z} 136,123,93)$ & $<$ LOD & - & - & - & - & - \\
\hline 1467 & - & n.i. sesquiterpene $(m / z 136,121,93)$ & - & - & 1.4 & $(17)$ & 1.2 & $(14)$ \\
\hline 1476 & 1475 & $\beta$-Chamigrene & 0.5 & $(20)$ & - & - & - & - \\
\hline 1490 & 1568 & Nerolidol & 6.7 & (6) & - & - & 29.2 & $(15)$ \\
\hline 1620 & - & n.i. sesquiterpene $(\mathrm{m} / \mathrm{z} 189,204,161)$ & $<$ LOD & - & 1.4 & $(12)$ & 1.2 & $(14)$ \\
\hline 1641 & - & n.i. sesquiterpene $(\mathrm{m} / \mathrm{z} 93,121,107)$ & $<$ LOD & - & 0.9 & $(4)$ & 1.1 & $(17)$ \\
\hline 1649 & - & $(E, Z)$ - $\alpha$-Farnesene & 4.2 & (6) & - & - & - & - \\
\hline 1650 & - & n.i. sesquiterpene $(\mathrm{m} / \mathrm{z} 93,119,204)$ & 0.2 & (22) & - & - & - & - \\
\hline 1690 & - & Guaiazulene & 0.2 & - & - & - & - & - \\
\hline 1829 & 1742 & $(E, Z)$-Farnesol & $<\mathrm{LOD}$ & - & - & - & 84.1 & $(16)$ \\
\hline 1873 & - & n.i. sesquiterpene $(m / z \quad 161,189,204)$ & $<$ LOD & - & - & - & - & - \\
\hline Subto & $\left.L^{-1}\right)$ & & 11.7 & & 3.8 & & 116.8 & \\
\hline \multicolumn{9}{|c|}{$\mathrm{C}_{13}$ Norisoprenoids } \\
\hline 1242 & 1286 & Vitispirane & 12.0 & (8) & 34.3 & (79) & 16.4 & (3) \\
\hline 1278 & - & TDN (1,1,6-trimethyl-1,2-dihydronaphthalene) & 11.0 & $(22)$ & 34.5 & $(13)$ & 6.8 & $(4)$ \\
\hline 1397 & 1381 & E- $\beta$-Damascenone & 3.4 & $(13)$ & 2.1 & $(16)$ & 5.9 & $(52)$ \\
\hline 1611 & - & 2,5,8-Trimethyl-1,2-dihydronaphthalene & 2.1 & $(18)$ & - & - & - & - \\
\hline Subto & $\left.L^{-1}\right)$ & & 28.5 & & 70.9 & & 29.1 & \\
\hline \multicolumn{9}{|l|}{ Esters } \\
\hline 897 & - & Ethyl lactate & $<\mathrm{LOD}$ & - & - & - & - & - \\
\hline 911 & 857 & Ethyl 2-methyl butanoate & $<$ LOD & - & $<\mathrm{LOD}$ & - & 14.7 & $(12)$ \\
\hline 913 & 856 & Ethyl 3-methyl butanoate & $<\mathrm{LOD}$ & - & 9.7 & (7) & 32.5 & $(11)$ \\
\hline 924 & 876 & 3-Methyl-butylacetate & 8.5 & $(16)$ & 52.6 & (9) & 198.8 & (13) \\
\hline 925 & 880 & 2-Methyl-butylacetate & $<$ LOD & - & - & - & - & - \\
\hline 1006 & 1001 & Ethy hexanoate & 702.5 & $(16)$ & 943.7 & (9) & 203.2 & $(9)$ \\
\hline 1007 & 1014 & Hexyl acetate & - & - & 2.7 & (6) & $<\mathrm{LOD}$ & - \\
\hline 1020 & - & Ethyl 2-hexenoate & - & - & $<\mathrm{LOD}$ & - & - & - \\
\hline 1046 & - & Ethy heptadecanoate & - & - & $<\mathrm{LOD}$ & - & $<\mathrm{LOD}$ & - \\
\hline 1067 & 1126 & Methyl octanoate & $<\mathrm{LOD}$ & - & $<\mathrm{LOD}$ & - & $<\mathrm{LOD}$ & - \\
\hline 1099 & 1167 & Diethyl succinate (diethyl butanedioate) & 180.5 & (19) & 227.7 & $(10)$ & 536.7 & (13) \\
\hline 1209 & 1196 & Ethyl octanoate & 706.3 & $(22)$ & 1092.3 & $(12)$ & 171.0 & $(4)$ \\
\hline 1228 & 1244 & Ethyl phenylacetate & 2.4 & $(43)$ & 3.4 & $(15)$ & 5.0 & $(16)$ \\
\hline 1233 & - & 3-Methylbutyl octanoate + n.i. $(\mathrm{m} / \mathrm{z} 87,59,104)$ & 3.0 & (9) & - & - & 3.5 & (5) \\
\hline 1234 & 1256 & 2-Phenylethylacetate & 4.0 & $(47)$ & 3.9 & $(23)$ & 7.9 & $(16)$ \\
\hline 1242 & - & n.i. ester $(m / z 117,71,89)$ & 2.5 & $(50)$ & - & - & - & - \\
\hline 1250 & - & n.i. ester $(m / z$ 88, 138, 101) & - & - & 5.3 & $(18)$ & 4.1 & $(6)$ \\
\hline 1275 & - & Di-isobutyl succinate & 2.3 & $(16)$ & 2.5 & (12) & 5.1 & (16) \\
\hline 1282 & - & 2-Methylpropyl octanoate & 2.3 & $(15)$ & 2.6 & $(4)$ & - & - \\
\hline 1403 & - & Ethyl 9-decenoate & 3.2 & (7) & - & - & 6.1 & (15) \\
\hline 1408 & 1397 & Ethyl decanoate & 136.0 & $(20)$ & 397.5 & $(16)$ & 36.1 & (13) \\
\hline
\end{tabular}


Table 2 (Continued)

\begin{tabular}{|c|c|c|c|c|c|c|c|c|}
\hline \multirow{3}{*}{$\begin{array}{r}\mathrm{RI}_{\text {calc }}{ }^{\mathrm{a}} \\
1425\end{array}$} & \multirow{3}{*}{$\begin{array}{r}\mathrm{RI}_{\text {lit }}{ }^{\mathrm{b}} \\
-\end{array}$} & \multirow{3}{*}{$\begin{array}{c}\text { Volatile compounds } \\
\text { Ethyl 3-methylbutyl butanedioate }\end{array}$} & \multicolumn{6}{|c|}{ Concentration $\left(\mu \mathrm{gL}^{-1}\right)$} \\
\hline & & & \multicolumn{2}{|c|}{ WSW } & \multicolumn{2}{|c|}{ WTW } & \multicolumn{2}{|c|}{ RTW } \\
\hline & & & 6.2 & (26) & 12.5 & (10) & 44.9 & (85) \\
\hline 1433 & - & 2-Methylbutyl octanoate & 3.1 & (26) & 5.7 & (23) & 3.2 & (3) \\
\hline 1608 & 1597 & Ethyl dodecanoate & 3.8 & (23) & 9.0 & (16) & 4.2 & (22) \\
\hline 1628 & - & 2-Phenylethylbutanoate & 2.3 & (16) & - & - & - & - \\
\hline 1633 & - & 2-Methylbutyl decanoate & 2.3 & (19) & 3.8 & (4) & - & - \\
\hline 1686 & 1762 & Benzylbenzoate & 2.4 & (15) & - & - & - & - \\
\hline 1825 & - & 2-Phenylethyl hexanoate & 2.6 & (38) & - & - & 8.2 & (64) \\
\hline 1833 & - & 2-Phenylethyl decanoate & 2.4 & (15) & - & - & - & - \\
\hline Subtotal $\left(\mu \mathrm{gL}^{-1}\right)$ & & & 1778.5 & & 2775.1 & & 1285.4 & \\
\hline \multicolumn{9}{|l|}{ Alcohols } \\
\hline 920 & 867 & Hexanol & $<\mathrm{LOD}$ & - & 1101.9 & (17) & 904.3 & (14) \\
\hline 1012 & - & 2-Ethylhexanol & - & - & - & - & 60.8 & (6) \\
\hline 1016 & - & Benzyl alcohol & - & - & - & - & $<\mathrm{LOD}$ & - \\
\hline 1021 & - & 3,5,5-Trimethyl-1-hexanol & - & - & - & - & 251.7 & (18) \\
\hline 1031 & - & 3-Ethyl-2-pentanol & - & - & - & - & 462.8 & (15) \\
\hline 1034 & - & Octanol & - & - & - & - & $<\mathrm{LOD}$ & - \\
\hline 1058 & 1118 & 2-Phenylethanol & 41686.5 & $(42)$ & 47732.7 & (16) & 247190.1 & (15) \\
\hline 1237 & 1263 & Decanol & - & - & 195.0 & (30) & - & - \\
\hline 1252 & - & 2-Undecanol & - & - & - & - & 80.3 & (10) \\
\hline Subtotal $\left(\mu \mathrm{gL}^{-1}\right)$ & & & 41686.5 & & 49029.6 & & 248950.0 & \\
\hline \multicolumn{3}{|c|}{ Total volatile compounds $\left(\mu \mathrm{gL}^{-1}\right)$} & 43761.4 & & 52926.9 & & 250615.6 & \\
\hline
\end{tabular}

contribution to the varietal aroma peculiarities and biological activities. The optimised methodology allowed to quantify a large number of varietal volatile compounds (monoterpenoids, sesquiterpenoids, and $\mathrm{C}_{13}$ norisoprenoids), 29 from the total 67 compounds. As expected, the WTW accounted for the higher number (12) and concentration of monoterpenoids $\left(1047.6 \mu \mathrm{gL}^{-1}\right)$, followed by the WSW (eight compounds, $256.3 \mu \mathrm{gL}^{-1}$ ) and RTW (four compounds, $234.3 \mu \mathrm{gL}^{-1}$ ). As the monoterpenoids are secondary metabolites whose synthesis is encoded by variety-related genes, the terpenoid profile may be used as a way to trace the varietal origin [15]. The sesquiterpenoids were also reported as an important chemical group present in Vitis vinifera L. due to their aroma properties and also bioactive effect as anti-bacterial activity [16] or the ability to enhance bacterial permeability and susceptibility to exogenous antimicrobial compounds [17], being present especially in red varieties $[18,19]$. Table 2 shows that the higher concentration of sesquiterpenoids was observed in the RTW $\left(116.8 \mu \mathrm{gL}^{-1}\right)$, followed by WSW $\left(11.7 \mu \mathrm{gL}^{-1}\right)$ and WTW $\left(3.8 \mu \mathrm{gL}^{-1}\right)$. Nerolidol and $(E, Z)-\alpha$-farnesol were the main sesquiterpenoids quantified. These compounds have been reported to occur as volatile components of some wines, being their origin also resultant of yeast activity during alcoholic fermentation [20]. $\beta$-Chamigrene and guaiazulene, detected only in WSW, are described for the first time as wine constituents. Four different $C_{13}$ norisoprenoids were detected, the higher concentration was observed in the WTW $\left(70.9 \mu \mathrm{gL}^{-1}\right)$ and similar concentrations were accounted for RTW $\left(29.1 \mu \mathrm{gL}^{-1}\right)$ and WSW $\left(28.5 \mu \mathrm{gL}^{-1}\right)$.
The monoterpenoids, sesquiterpenoids, and $\mathrm{C}_{13}$ norisoprenoids represent, quantitatively, minor chemical families, have their origin in the grapes. These compounds have usually low perception limits (few $\mu \mathrm{gL}^{-1}$ ), however could have the higher impact on wine aroma properties [21,22]. E- $\beta$ damascenone has odour descriptors of apple and sweet [23], and backed apple [24] and its OT in wines is $0.05 \mu \mathrm{gL}^{-1}$ [25]. All the wines analysed exhibited concentrations above its OT, suggesting the contribution of this compound to the wines aroma. The OT of 2-phenylethanol is $14,000 \mu \mathrm{gL}^{-1}[26]$, and all the wines analysed exhibited concentrations above its OT, indicating that this compound contribute with roses note. The esters ethyl hexanoate and ethyl octanoate have fruity and anise as odour descriptors, and their OT are 5-14 $\mu \mathrm{gL}^{-1}$ and $2-5 \mu \mathrm{gL}^{-1}$, respectively $[25,26]$. All the wines analysed exhibited concentrations higher than their OT, suggesting their individual contribution to the wine aroma. Furthermore, the sensorial contribution to the overall aroma of a substance, when its concentration is at least $20 \%$ of the OT should be considered [27].

$\mathrm{C}_{6}$ alcohols have herbaceous and greasy odours, which have been related to deleterious effects in the wines, although in white wines a small herbaceous perception is appreciated by some consumers. Their origin has been reported to be related mainly to the lipooxygenase activity of the grape and/or must aeration. The limit of perception for hexanol was estimated as $8 \mathrm{mgL}^{-1}$ (Table 1). According to Table 2, hexanol was above its OT in all wines analysed and a contribution to an herbaceous aroma may not be excluded. 


\section{Conclusions}

In the present work, stir bar sorptive extraction with liquid desorption followed by large volume injection and capillary gas chromatography coupled to quadrupole mass spectrometry (SBSE-LD/LVI-GC-qMS) was applied for the first time in the analysis of the volatile fraction of wine samples. The main parameters that are known to influence the methodology are fully discussed, such as liquid desorption and large volume injection parameters. According to the results obtained, the SBSE-LD/LVI-GC-qMS optimised experimental conditions were established: 60 min of extraction time, $10 \%$ ethanol content, pentane as desorption solvent, $15 \mathrm{~min}$ for the back-extraction period, $10 \mathrm{~mL} \mathrm{~min}^{-1}$ for the solvent vent flow rate and $10^{\circ} \mathrm{C}$ for the inlet temperature. The method proposed showed good linearity over the concentration range tested, with correlation coefficients higher than 0.9821 , a good reproducibility was attained (8.9-17.8\%) and, additionally, low detection limits were achieved for nine volatile compounds (0.05-9.09 $\left.\mu \mathrm{gL}^{-1}\right)$, with the exception of 2-phenylethanol due to its low recovery by SBSE.

The SBSE-LD/LVI-GC-qMS methodology allowed, in a single run, the quantification of 67 wine volatiles that can be quantified accurately at levels lower than their respective olfactory thresholds. This type of information can be used to infer the potential contribution of the volatile compounds to the wine's aroma properties. This methodology showed great sensibility for the varietal compounds that only comprised ca. $1-2 \%$ of volatile fraction of wines. The deep discussion covering the experimental parameters involved in this methodology allows its extension to other types of beverages, as well as other liquid matrices.

\section{Acknowledgements}

This work was financially supported by AGRO $\mathrm{N}^{\circ} 38$ and Fundação para a Ciência e a Tecnologia (SFRH/BD/25336/2005).

\section{R E F E R E N C E S}

[1] A. Rapp, Nahrung 42 (1998) 351.

[2] L. Pillonel, J.O. Bosset, R. Tabacchi, Lebensm.-Wiss. und-Technol. 35 (2002) 1.

[3] R.F. Alves, A.M.D. Nascimento, J.M.F. Nogueira, Anal. Chim. Acta 546 (2005) 11.
[4] A. Zalacain, J. Marin, G.L. Alonso, M.R. Salinas, Talanta 71 (2007) 1610.

[5] E. Baltussen, P. Sandra, F. David, C. Cramers, J. Microcolumn Sep. 11 (1999) 737.

[6] P. Serôdio, M.S. Cabral, J.M.F. Nogueira, J. Chromatogr. A 1141 (2007) 259.

[7] P. Serôdio, J.M.F. Nogueira, Anal. Chim. Acta 517 (2004) 21.

[8] P. Serôdio, J.M.F. Nogueira, Anal. Bioanal. Chem. 382 (2005) 1141.

[9] P. Serôdio, J.M.F. Nogueira, Water Res. 40 (2006) 2572.

[10] J. Marin, A. Zalacain, C. De Miguel, G.L. Alonso, M.R. Salinas, J. Chromatogr. A 1098 (2005) 1.

[11] J. Diez, C. Dominguez, D.A. Guillen, R. Veas, C.G. Barroso, J. Chromatogr. A 1025 (2004) 263.

[12] W. Meylan, SRC KOWWIN Software SRC-LOGKOW, Syracuse Research Corporation, USA, NY, 2000.

[13] D.R. Lide, CRC Handbook of Chemistry and Physics, CRC Press, Boca Raton, FL, 2005.

[14] V.M. Leon, B. Alvarez, M.A. Cobollo, S. Munoz, I. Valor, J. Chromatogr. A 999 (2003) 91.

[15] S.M. Rocha, E. Coelho, J. Zrostlikova, I. Delgadillo, M.A. Coimbra, J. Chromatogr. A 1161 (2007) 292.

[16] K. Tamemoto, Y. Takaishi, B. Chen, K. Kawazoe, H. Shibata, T. Higuti, G. Honda, M. Ito, Y. Takeda, O.K. Kodzhimatov, O. Ashurmetov, Phytochemistry 58 (2001) 763.

[17] B.F. Brehm-Stecher, E.A. Johnson, Antimicrob. Agents Chemother. 47 (2003) 3357.

[18] E. Coelho, S.M. Rocha, I. Delgadillo, M.A. Coimbra, Anal. Chim. Acta 563 (2006) 204.

[19] S.M. Rocha, E. Coelho, J.R. Vinholes, M.A. Coimbra, in: V.K. Singh, J.N. Govil, K. Ahmad, R.K. Sharma (Eds.), Recent Progress in Medicinal Plants, Studium Press, LLC, U.S.A., Houston, 2006, p. 253.

[20] L. Zea, J. Moreno, J.M. Ortega, M. Medina, J. Agric. Food Chem. 43 (1995) 1110

[21] S.M. Rocha, P. Coutinho, I. Delgadillo, A. Dias Cardoso, M.A. Coimbra, J. Sci. Food Agric. 85 (2005) 199.

[22] E. Coelho, S.M. Rocha, A.S. Barros, I. Delgadillo, M.A. Coimbra, Anal. Chim. Acta 597 (2007) 257.

[23] A. Escudero, B. Gogorza, M.A. Melus, N. Ortin, J. Cacho, V. Ferreira, J. Agric. Food Chem. 52 (2004) 3516.

[24] L. Cullere, A. Escudero, J. Cacho, V. Ferreira, J. Agric. Food Chem. 52 (2004) 1653.

[25] H. Guth, J. Agric. Food Chem. 45 (1997) 3027.

[26] V. Ferreira, R. López, J.F. Cacho, J. Sci. Food Agric. 80 (2000) 1659.

[27] S.M. Rocha, F. Rodrigues, P. Coutinho, I. Delgadillo, M.A. Coimbra, Anal. Chim. Acta 513 (2004) 257.

[28] G. Ohloff, Perfum. Flavor. 3 (1978) 11.

[29] R.G. Buttery, J.G. Turnbaugh, L.C. Ling, J. Agric. Food Chem. 36 (1988) 1006 